\title{
RADIOCARBON DATING OF IRON: A NORTHERN CONTRIBUTION
}

\author{
M Oinonen ${ }^{1,2} \bullet$ G Haggren $^{3} \bullet$ A Kaskela $^{1} \cdot \mathrm{M} \mathrm{Lavento}^{3} \bullet$ V Palonen $^{4} \bullet$ P Tikkanen $^{4}$ \\ ABSTRACT. The iron dating project Aikarauta has been launched in Finland. This paper presents the results of the prelim- \\ inary investigations. The ability for radiocarbon measurement by accelerator mass spectrometry (AMS) of iron in Finland has \\ been demonstrated by using coal-produced iron as reference material. An elemental analyzer has been harnessed to measure \\ the carbon content of small iron samples. In addition, we have hypothesized that a fingerprint of the limestone usage in the \\ smelting process is the high $\mathrm{Ca}$ content of iron and slag. This has been examined by performing an iron smelting experiment \\ with limestone as flux, by making elemental analyses of ingredients and the resulting slag and iron, and by a ${ }^{14} \mathrm{C}$ analysis of \\ the produced iron. It is possible that limestone dilutes the ${ }^{14} \mathrm{C}$ contents of the produced iron, making its age determination \\ challenging.
}

\section{INTRODUCTION}

Absolute chronologies in archaeology have often been built on radiocarbon dating of contexts. The more solid dating method for archaeological material is, however, to date objects themselves. Iron and iron slag findings are of crucial importance for the Iron Age and Middle Age studies. Reliable dating of iron objects and iron slag would provide a tool to unambiguously link the human activity and its time of occurrence to the context in question. The more accurate this data would be the more solid would also be many other interpretations which are dependent on the exact chronology.

Various iron smelting processes yield $0-4 \%$ contents of carbon inside the iron matrix. If the fuel used in the process has been charcoal, the amount of ${ }^{14} \mathrm{C}$ inside the iron matrix reflects the time of manufacturing of the object. ${ }^{14} \mathrm{C}$ dating of iron objects has been pioneered by van der Merwe (1969). Accelerator mass spectrometry (AMS) has made it possible to date iron for orders of magnitude smaller samples (e.g. Cook et al. 2001; Hüls et al. 2004; Scharf et al. 2004).

The own age of charcoal may induce systematically older ${ }^{14} \mathrm{C}$ ages. Success in dating may be related also to other materials involved. Flux may be used to remove the impurities from the process. For example, limestone (calcium carbonate) has been suggested to be used already by a 200 -yr-old recipe (Rinman 1794:47). Since the origin of the carbonate carbon maybe fossil, one should be aware of its capability to dilute the amount of ${ }^{14} \mathrm{C}$ in the resulting iron and slag.

Motivated by the earlier works and the needs of the local archaeological community (e.g. Lavento 1999), we have launched the iron dating project Aikarauta in Finland. As part of the project, several aims have been set up for the present work. The first is to demonstrate the ability for AMS ${ }^{14} \mathrm{C}$ measurements of iron in Finland. The second aim is to establish carbon content measurements by an elemental analyzer. Finally, we have initiated studies on the role of limestone as a possible source of error in the ${ }^{14} \mathrm{C}$ measurements of iron. We hypothesize that a fingerprint of the limestone usage in the smelting process is the high $\mathrm{Ca}$ contents of iron and slag. We aim to confirm the set hypothesis by an iron smelting experiment in which limestone is used as flux and by making elemental analyses of the ingredients and resulting slag and iron. The importance of the limestone flux has been studied also by a ${ }^{14} \mathrm{C}$ analysis of the produced iron.

\footnotetext{
${ }^{1}$ Dating Laboratory, Finnish Museum of Natural History, University of Helsinki, Finland.

${ }^{2}$ Corresponding author. Email: markku.j.oinonen@helsinki.fi.

${ }^{3}$ Department of Archaeology, University of Helsinki, Finland.

${ }^{4}$ Department of Physics, University of Helsinki, Finland.
}

(C) 2009 by the Arizona Board of Regents on behalf of the University of Arizona Proceedings of the 5th International ${ }^{14} \mathrm{C}$ and Archaeology Symposium, edited by Irka Hajdas et al. RADIOCARBON, Vol 51, Nr 2, 2009, p 873-881 
Eventually, all this preliminary work will serve a larger goal: to carefully develop and scrutinize the method of ${ }^{14} \mathrm{C}$ dating of iron in Finland to be able to extend the research capabilities for Iron Age and Medieval studies.

\section{EXPERIMENTAL METHODS}

\section{Iron Smelting Process}

Essentially, the iron smelting process has remained the same throughout the ages. An 18th century recipe (Rinman 1794) describes a method used by peasant iron-smelters to produce iron from bog or lake ore. It is based on the practical expertise of the iron smelters of eastern Finland (Peets 2003: 33 ), very probably in western Finland as well, and provides an insight into the early iron craftsmanship in the regions. The discussion of the smelting process below is based on the work of Pleiner (2000:133-6).

The temperature inside a typical furnace ranges from $300^{\circ} \mathrm{C}$ (top) to $>1400^{\circ} \mathrm{C}$ (at the air inlet level). Typical chemical reactions involved in a smelting process are as follows. First, the available carbon reacts with oxygen and forms carbon monoxide.

$$
6 \mathrm{C}+3 \mathrm{O}_{2} \rightarrow 6 \mathrm{CO}
$$

Carbon and the carbon monoxide reduce the iron from its oxide and carbon dioxide is produced:

$$
\begin{gathered}
3 \mathrm{C}+\mathrm{Fe}_{2} \mathrm{O}_{3} \rightarrow 2 \mathrm{Fe}+3 \mathrm{CO} \\
6 \mathrm{CO}+2 \mathrm{Fe}_{2} \mathrm{O}_{3} \rightarrow 4 \mathrm{Fe}+6 \mathrm{CO}_{2}
\end{gathered}
$$

Carburization of iron occurs primarily above $900{ }^{\circ} \mathrm{C}$ either by carbon absorption from $\mathrm{CO}$ gas or directly. At these extreme temperatures, very high-carbon cast iron can be produced:

$$
\begin{gathered}
3 \mathrm{Fe}+2 \mathrm{CO} \rightarrow \mathrm{Fe}_{3} \mathrm{C}+\mathrm{CO}_{2} \\
3 \mathrm{Fe}+\mathrm{C} \rightarrow \mathrm{Fe}_{3} \mathrm{C}
\end{gathered}
$$

Slag is formed mostly as fayalite $\left(\mathrm{FeO} \cdot \mathrm{SiO}_{2}\right)$. If limestone is used as flux, its calcium ends up mainly inside the iron slag as silicates:

$$
\begin{gathered}
\mathrm{CaCO}_{3} \rightarrow \mathrm{CaO}+\mathrm{CO}_{2} \\
\mathrm{CaO}+\mathrm{SiO}_{2} \rightarrow \mathrm{CaSiO}_{3}
\end{gathered}
$$

\section{Iron Smelting Experiment}

An iron smelting experiment based on a 200-yr-old recipe (Rinman 1794) was performed to explore the role of limestone in the process. The smelting furnace was constructed of light gravel blocks (Figure 1) used in chimneys and covered with firebricks.

During the smelting process, the furnace is loaded from the top with charcoal and (roasted) iron ore. Air is directed into the process from below via a tuyere. Iron ore grains fall through a matrix formed by the added charcoal and against a flow of reducing gases (mainly $\mathrm{CO}$ ). During the process, iron oxides in the ore reduce to iron within the furnace volume and the reduced iron particles fall into a liquid bath of slag formed near the air inlet. Eventually, iron-being denser than slag-ends up at the bottom of the furnace and sticks together. Therefore, a sponge of iron forms at the bottom of the furnace. Slag is drained through a temporarily closed opening at the lower side of the furnace. 


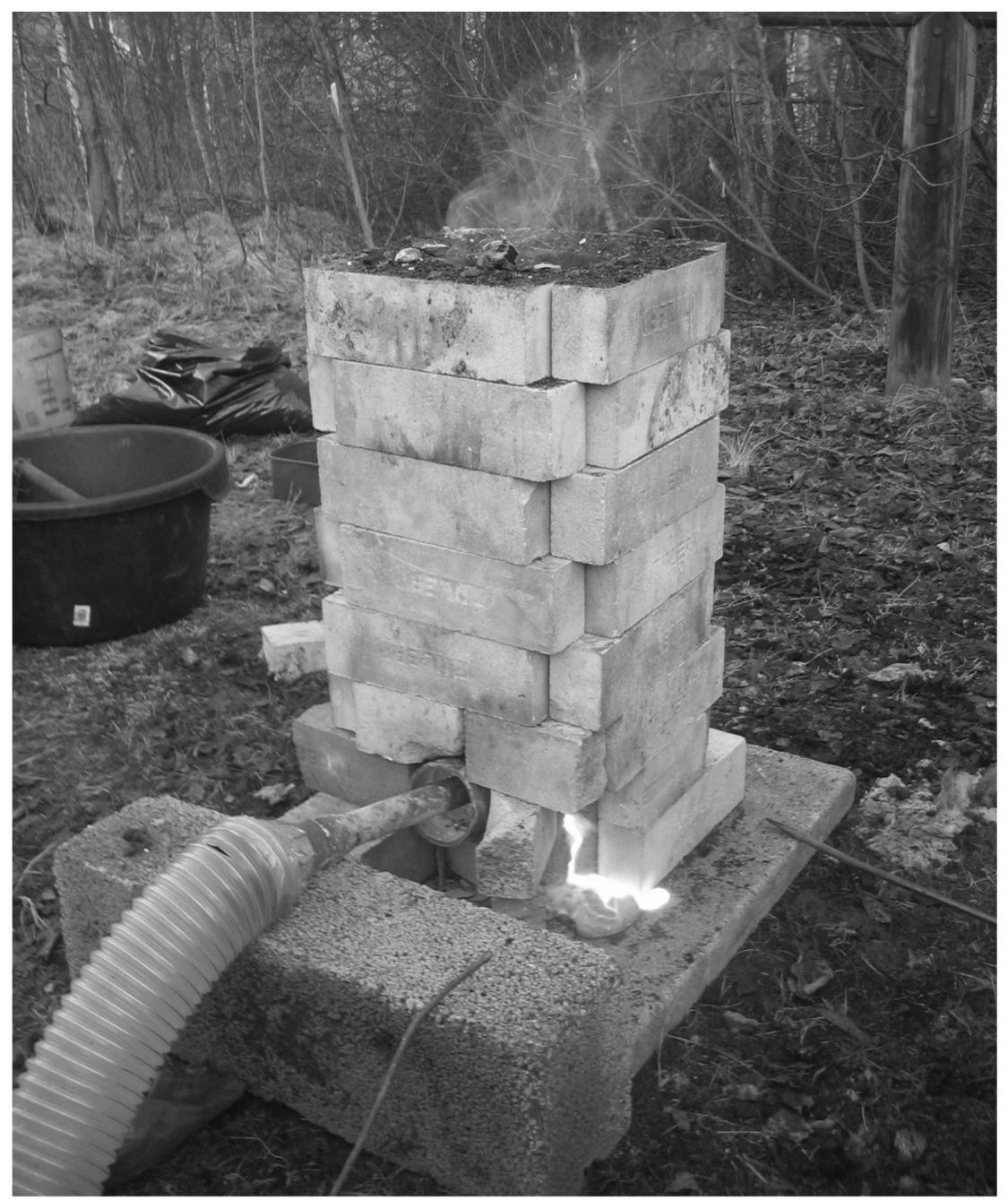

Figure 1 Furnace used in the iron smelting experiment. The furnace is constructed with lightgravel blocks surrounded by firebricks. A blower supplies air into the process. In the figure, the molten slag is draining out from the process via an opening at the lower right-hand side of the furnace.

To fix the ${ }^{14} \mathrm{C}$ content of the used charcoal close to the present atmospheric value, the wood of which the charcoal was produced was chosen to be $<10 \mathrm{yr}$ old. The smelting process used $5.7 \mathrm{~kg}$ of this charcoal (referred to as PH-1 in the tables), $6.3 \mathrm{~kg}$ ore (MA-1), and $0.44 \mathrm{~kg}$ of commercial limestone (KK-1). The ingredients were added inside the furnace from the top by preselected amounts every $\sim 10 \mathrm{~min}$. The smelting continued for a total of $1.5 \mathrm{hr}$ and resulted in $0.8 \mathrm{~kg}$ of iron lump (OMA-1). The weight of the produced slag (KU-3) was $5.5 \mathrm{~kg}$.

\section{Reference Samples}

Six reference samples (RR-1 to RR-6) produced with fossil coal were provided by Rautaruukki Oyj (Helsinki, Finland). The carbon content of the reference samples varied from 0.13 to $4.7 \%$. These were used to study the sample treatment process. Since the coal-based process should not introduce 
any ${ }^{14} \mathrm{C}$ into the resulting iron, these samples were also used to study the maximal background of the process. Particularly, high-carbon samples of RR-6 were used for process development.

\section{Elemental Analyses}

The reference samples were also used to test a method for estimating the carbon content of the iron samples. Six samples of $0.35-0.70 \mathrm{mg}$ of high-carbon iron RR-6 $(\mathrm{C} \%=3.92 \%)$ were combusted in an elemental analyzer (EA) ThermoQuest NC2500 and the carbon contents were measured. To reveal the carbon integration in the ore due to the roasting process, the elemental analyzer was also used to measure the carbon content of the roasted ore. In addition, the ICP-OES technique was used to study the Ca contents of limestone, ore, iron, and slag. We assumed that dissolving the samplesa built-in property of the ICP-OES method-would provide homogeneous samples for elemental analyses.

\section{Sample Treatment for AMS}

Typically, the ${ }^{14} \mathrm{C}$ samples in the laboratory are combusted inside an evacuated glass ampoule with $\mathrm{CuO}$ grains. Thus, for iron samples it is reasonable to follow the similar sample treatment pioneered by Cook et al. (2001) and developed further by Hüls et al. (2004).

During the project, the sample treatment developed according to Table 1 from A to C. Treatments A1,2 used a standard milling machine and oil to grind the samples into thin chips. Treatments $\mathrm{B}$ and $\mathrm{C}$ aimed to minimize external carbon involvement in the procedure and used $\mathrm{Al}_{2} \mathrm{O}_{3}$ grinding wheels to first mechanically clean and then sample the iron. After polishing, the grinding wheel was changed to minimize potential contamination. The extracted iron grains were then picked up on a weighing paper by a strong magnet.

Table 1 Sample treatment procedures used for the iron samples during the process development. US = ultrasonic bath.

\begin{tabular}{|c|c|c|c|c|}
\hline Step & Treatment A-1 & Treatment A-2 & Treatment B & Treatment C \\
\hline $\begin{array}{l}\text { Mechanical } \\
\text { cleaning }\end{array}$ & & & $\begin{array}{l}\text { Polishing by } \mathrm{Al}_{2} \mathrm{O}_{3} \\
\text { wheel }\end{array}$ & $\begin{array}{l}\text { Polishing by } \mathrm{Al}_{2} \mathrm{O}_{3} \\
\text { wheel }\end{array}$ \\
\hline Sampling & $\begin{array}{l}\text { Milling machine }+ \text { oil } \\
\text { (chips) }\end{array}$ & $\begin{array}{l}\text { Milling machine }+ \text { oil } \\
\text { (chips) }\end{array}$ & $\begin{array}{l}\text { Grinding by } \mathrm{Al}_{2} \mathrm{O}_{3} \\
\text { wheel (grains) }\end{array}$ & $\begin{array}{l}\text { Grinding by } \mathrm{Al}_{2} \mathrm{O}_{3} \\
\text { wheel (grains) }\end{array}$ \\
\hline Cleaning_1 & Toluene $12 \mathrm{hr}$ & Toluene $12 \mathrm{hr}$ & $\mathrm{H}_{2} \mathrm{O} \times 2$ & $\mathrm{H}_{2} \mathrm{O} \times 2$ \\
\hline Cleaning_2 & Toluene + US $15 \mathrm{~min}$ & Toluene + US $15 \mathrm{~min}$ & $\mathrm{H}_{2} \mathrm{O}+\mathrm{US} 15 \mathrm{~min}$ & $\mathrm{H}_{2} \mathrm{O}+\mathrm{US} 15 \mathrm{~min}$ \\
\hline Cleaning_3 & $\begin{array}{l}\text { (Acetone + US } 15 \mathrm{~min} \text { ) } \\
\times 2\end{array}$ & $\begin{array}{l}\text { (Acetone + US } 15 \mathrm{~min} \text { ) } \\
\times 2\end{array}$ & $\mathrm{H}_{2} \mathrm{O} \times 2$ & $\mathrm{H}_{2} \mathrm{O} \times 2$ \\
\hline Cleaning_4 & Acetone $\times 2$ & Acetone $\times 2$ & & Acetone \\
\hline Cleaning_5 & & $10 \% \mathrm{HNO}_{3}$ etching & & Acetone + US $15 \mathrm{~min}$ \\
\hline Cleaning_6 & & $\mathrm{H}_{2} \mathrm{O}$ until neutral & & Acetone \\
\hline Cleaning_7 & & $\mathrm{EtOH}$ & & \\
\hline Drying & @ $90^{\circ} \mathrm{C}$ & @ $90^{\circ} \mathrm{C}$ & $@ 90^{\circ} \mathrm{C}$ in vacuum & @ $90^{\circ} \mathrm{C}$ in vacuum \\
\hline
\end{tabular}

Sample cleaning in the treatment A-1 couples toluene washes and the typical procedure to perform cleaning of aluminum AMS cathodes to improve dissolution of the milling oil. Due to the spongelike structure of the OMA-1 sample, $\mathrm{HNO}_{3}$ etching was further added to treatment A-2 to enhance the removal of the possible surface contaminants (oil remnants, abrasive products, etc). The treatment $\mathrm{B}$ aimed to introduce a completely carbon-free process by using only distilled $\mathrm{H}_{2} \mathrm{O}$ washes. An acetone wash was added for the treatment $\mathrm{C}$. As a precautionary measure, the treatments $\mathrm{B}$ and $\mathrm{C}$ used a vacuum oven for drying to minimize possible rusting due to the use of distilled water during the processes. 
An aliquot of the cleaned sample — corresponding to $\sim 1 \mathrm{mg}$ of pure graphite—was packed inside a 6mm-diameter quartz tube with an excess of $\mathrm{CuO}$ (mass $>5 \times$ the sample mass). The $6-\mathrm{mm}$ tube was placed inside a $9-\mathrm{mm}$ one and the installation sealed under vacuum. The double-tube arrangement was then combusted in $1000^{\circ} \mathrm{C}$ for $10 \mathrm{hr}$. After purifying and measuring its $\delta^{13} \mathrm{C}$ value, the resulting $\mathrm{CO}_{2}$ was converted to graphite in the presence of zinc powder and iron catalyst. The ${ }^{14} \mathrm{C}$ age was finally determined with the AMS technique on the graphite target.

The pretreatment for the ingredients for the iron smelting (charcoal, roasted iron ore, limestone) was minimal aiming the ${ }^{14} \mathrm{C}$ contents to precisely reflect the smelting experiment. The ore was combusted in the same way as iron samples but the charcoal in a glass ampoule at $520^{\circ} \mathrm{C}$ for $10 \mathrm{hr}$. Carbon dioxide from the limestone sample was released with $85 \% \mathrm{H}_{3} \mathrm{PO}_{4}$. Otherwise the treatment followed the standard procedure to obtain graphite targets described above.

\section{AMS Measurements}

AMS measurements were performed with the Helsinki AMS at the Materials Physics Division of the University of Helsinki (Tikkanen et al. 2004; Palonen and Tikkanen 2007). Control measurements were performed also at the Uppsala Tandem Laboratory for the reference samples. The ${ }^{14} \mathrm{C}$ contents are expressed as pMC (Stuiver and Polach 1977) and are corrected for isotopic fractionation (see Table 2 for other details).

Table 2 Results of the ${ }^{14} \mathrm{C}$ analyses. The results are corrected for background of $38 \pm 2 \mathrm{kyr} \mathrm{BP}$, if not stated otherwise $(*=$ not corrected for background).

\begin{tabular}{lclllc}
\hline Sample & $\begin{array}{l}\text { C content } \\
(\%)\end{array}$ & AMS lab & $\begin{array}{l}\delta^{13} \mathrm{C} \\
(\%)\end{array}$ & $\begin{array}{l}\text { Age } \\
(\mathrm{BP})\end{array}$ & $\begin{array}{l}\mathrm{pMC} \\
(\%)\end{array}$ \\
\hline Iron RR-6 (A-1) & 3.92 & Upps & -24.9 & $34,240 \pm 150^{*}$ & $1.4 \pm 0.1^{*}$ \\
& & Hels & & $32,340+490 /-480^{*}$ & $1.8+0.2 /-0.2^{*}$ \\
Iron RR-6 (B) & 3.92 & Hels & -25.0 & $30,900+300 /-300^{*}$ & $2.1+0.1 /-0.1^{*}$ \\
Iron RR-6 (C) & 3.92 & Hels & -24.9 & $33,770+310 /-310^{*}$ & $1.5+0.1 /-0.1^{*}$ \\
Charcoal PH-1 & & Hels & -27.5 & $>$ Modern & $101.4 \pm 1.5$ \\
Limestone KK-1 & & Hels & +0.2 & $38,600 \pm 450^{*}$ & $0.8 \pm 0.1^{*}$ \\
Roasted ore MA-1 & 1.9 & Hels & -27.2 & $>$ Modern & $106.8 \pm 1.0$ \\
Iron OMA-1 \#1 (A-2) & $\sim 0.1$ & Hels & -25.1 & $2060 \pm 110$ & $77.3 \pm 1.1$ \\
Iron OMA-1 \#2 (A-2) & $\sim 0.1$ & Hels & -26.2 & $2330 \pm 120$ & $74.8 \pm 1.1$ \\
\hline
\end{tabular}

Instrumental drift was present in the measurements. The attained $1.1 \mathrm{pMC}$ average precision consisted of the statistical uncertainty and on average a $1.5 \%$ machine uncertainty per measurement. The AMS machine background is better than $0.015 \mathrm{pMC}$ (70 kyr BP).

Analysis of the measurement data was done with the Bayesian CAR model (Palonen and Tikkanen 2007). Due to the natural combination of the statistical error with the observed sampling variance and due to several smaller advantages, the uncertainties given by the CAR model are more reliable than the uncertainties given by mean-based methods (Palonen 2008). In addition, in the CAR model the measurement run is analyzed as a whole. As a result, the performance of the AMS machine can be monitored in much more detail. In these measurements, the machine error was correlated, with a correlation coefficient of 0.8 between the machine errors of subsequent measurements.

\section{RESULTS AND DISCUSSION}

The average of 6 measurements for the carbon content of RR- 6 samples by elemental analyzer is $3.70 \pm 0.12 \mathrm{wt} \%$. This agrees reasonably well with the value given by the manufacturer: $3.92 \%$. The 
small standard deviation demonstrates the good reproducibility of the measurements. Measurements of such a carbon content require only $<0.1 \mathrm{~mm}^{3}$ of material. Therefore, the technique has potential to allow for nearly non-destructive estimation of AMS ${ }^{14} \mathrm{C}$ measurements of iron objects via C-content determination. Exploring the limits of the technique in determining the $\mathrm{C} \%$ of low-carbon iron will is ongoing.

Roasting means a process of heating the lumps of ore in a fire at relatively low temperature of 400 $80{ }^{\circ} \mathrm{C}$ with free access of air (Pleiner 2000:107). Integration of pieces of charcoal is possible during the process and it may affect the eventual ${ }^{14} \mathrm{C}$ results of iron. The result of the EA measurement for the carbon content of the roasted ore is $1.9 \mathrm{wt} \%$. This was confirmed also by visual inspection of roasted ore: tiny pieces of charcoal were observed.

Experiments with samples of known carbon contents of 3.92\% (RR-6, Table 2) show that it is technically feasible to perform ${ }^{14} \mathrm{C}$ measurements of iron in Helsinki. The small set of measurements performed in this preliminary stage of the project urges us to be careful in making definite statements on the treatments. However, a few indications could be pointed out. The values are consistently larger compared to a generally adopted level of the process background of $\mathrm{pMC}_{\mathrm{BG}}=0.9 \pm$ $0.3 \%(38,000 \pm 2000 \mathrm{BP})$. This indicates possibly some atmospheric contamination within the coalbased iron smelting process of the reference samples. Concerning the sample treatment process, since the carbon-free treatment $\mathrm{B}$ excludes any fossil carbon contamination, the obtained value $\mathrm{pMC}_{\mathrm{RR}-6, \mathrm{~B}}=2.1^{+0.1}{ }_{-0.1} \%$ should reflect the maximal atmospheric contamination present during the treatments $\mathrm{B}$ and $\mathrm{C}$. Compared to treatment $\mathrm{B}$, treatment $\mathrm{C}$ with an acetone wash added appears to shift the result $\left(\mathrm{pMC}_{\mathrm{RR}-6, \mathrm{C}}=1.5^{+0.1}-0.1 \%\right)$ towards the range obtained for the treatment A-1 $\left(\mathrm{pMC}_{\mathrm{RR}-6, \mathrm{~A}-1}=1.4^{+0.1}-0.1-1.8^{+0.2}{ }_{-0.2} \%\right)$, which includes potential sources of fossil carbon contaminants like milling machine and oil (and toluene and acetone as cleaning solvents). Due to this similarity of the results, no ranking between the treatments A-1 and C could so far be inferred. Summarizing, all the adopted sample treatment processes for RR-6 samples yield ages in the range of 30,900-34,240 BP.

Regardless of the possible atmospheric carbon included in the reference samples, they offer a possibility to estimate the upper limit for the ${ }^{14} \mathrm{C}$ background obtained with the iron dating process in Finland so far. The median of the obtained age range is $32,570 \mathrm{BP}$ and compared to the typically adopted background level of $38,000 \mathrm{BP}$, it induces a +20 to $+40{ }^{14} \mathrm{C}$ yr systematic effect on typical Middle and Iron Age ${ }^{14} \mathrm{C}$ ages of around 500-2500 BP, respectively. This is of the same order as the typical statistical uncertainty of the ${ }^{14} \mathrm{C}$ measurement and forms a basis for future development.

Results of the elemental analyses of the smelted iron, its slag, and their constituents (limestone and roasted iron ore) are shown in Table 3. This analysis aimed to observe the Ca excesses due to limestone usage. The limestone and the RR-6 iron served as reference samples for elemental analyses. The ICP-OES results for the RR-6 iron reproduce fairly well the XRF results provided by the manufacturer. The Ca content of limestone is also well reproduced: theoretically it has a value of $40 /(40$ $+12+3 \times 16)=0.4$, i.e. $400,000 \mathrm{ppm}$, whereas the measured one is $360,000 \mathrm{ppm}$.

The high amount of $\mathrm{Ca}$ in the slag is outstanding. Taking into account the material masses involved in the process, Ca contents of the ore $(4400 \mathrm{ppm}$, i.e. $\sim 25 \mathrm{~g})$ cannot explain the observed amount of $\mathrm{Ca}$ in the slag: $26,000 \mathrm{ppm}$, i.e. $145 \mathrm{~g}$. The only possible source for such a high amount is the limestone: it supplies altogether $\sim 158 \mathrm{~g}$ of $\mathrm{Ca}$ to the process-an amount covering the observed $\mathrm{Ca}$ in the slag. The result, in line with equations 6 and 7, show that the Ca content of slag could possibly be used to identify the iron smelting cases where Ca-containing fluxes (limestone, for instance) have been used. 
Table 3 Results of the elemental analyses of manufactured iron, its slag, and their constituents with the ICP-OES technique. Limestone and RR-6 iron were measured as a reference. The theoretical value for the Ca contents of limestone is also given as well as the XRF results by the RR-6 iron manufacturer. The results are given as mass fractions in ppm.

\begin{tabular}{llrrrrrrrrr}
\hline Sample & Method & \multicolumn{1}{c}{$\mathrm{Ca}$} & $\mathrm{Cr}$ & $\mathrm{Cu}$ & $\mathrm{Pb}$ & $\mathrm{Mn}$ & $\mathrm{Ni}$ & $\mathrm{Si}$ & \multicolumn{1}{l}{$\mathrm{Ti}$} & \multicolumn{1}{l}{$\mathrm{V}$} \\
\hline Roasted ore MA-1 & ICP-OES & 4100 & 21 & 2 & 15 & 1600 & $<1$ & 730 & 120 & 110 \\
Slag KU-3 & ICP-OES & 26,000 & 15 & 40 & 11 & 2100 & $<1$ & 1200 & 150 & 79 \\
Iron OMA-1 & ICP-OES & 6300 & 9 & 25 & 440 & 560 & 18 & 4900 & 43 & $<1$ \\
Limestone KK-1 & ICP-OES & 360,000 & $<1$ & $<1$ & $<3$ & 44 & $<1$ & 92 & $<5$ & $<1$ \\
Limestone KK-1 & Theor. & 400,000 & - & - & - & - & - & - & - & - \\
Iron RR-6 & ICP-OES & $<30$ & 240 & 34 & 27 & 3000 & 270 & 800 & 170 & 1600 \\
Iron RR-6 & XRF & - & 310 & 100 & - & 3330 & 290 & 790 & 230 & 1800 \\
\hline
\end{tabular}

The involvement of limestone in the process can be discussed based on the typical temperature distribution within a smelting furnace. Inside the upper half of the furnace, temperatures typically reach $300-900{ }^{\circ} \mathrm{C}$, whereas inside the lower half, temperature ranges from 900 to $1400{ }^{\circ} \mathrm{C}$ (Pleiner 2000: 134). Within such a high-temperature environment, several process features need attention. The limestone $\left(\mathrm{CaCO}_{3}\right)$ starts to decompose at $840{ }^{\circ} \mathrm{C}$; therefore, its disintegration is most efficient within the lower half of the furnace. Furthermore, it starts to be involved in the slag-forming process at $1300-1400{ }^{\circ} \mathrm{C}$ (Tylecote 1987:329-30). Carburization at the high-temperature region is also enhanced compared to the low-temperature region (Pleiner 2000:134-5). Eventually, the reduced iron particles are stuck together, and an iron sponge is formed within this high-temperature region.

Our measurement of high Ca content of slag confirms a) the presence of high-temperature conditions inside the lower half of our furnace and b) the strong limestone involvement within the slagformation region. In light of these observations, it is not surprising that the determined Ca mass ratio between the produced iron and the used ore $\left(\mathrm{m}_{\mathrm{Ca}, \mathrm{OMA}-1} / \mathrm{m}_{\mathrm{Ca}, \mathrm{MA}-1}=0.20\right)$ is also higher compared to the plain mass ratio $\mathrm{m}_{\mathrm{OMA}-1} / \mathrm{m}_{\mathrm{MA}-1}=0.13$.

The observed ${ }^{14} \mathrm{C}$ ages for the OMA-1 iron produced with limestone as a flux are too old by 2060 $2330{ }^{14} \mathrm{C}$ yr and correspond to an amount of ${ }^{14} \mathrm{C}_{\mathrm{pMC}} \mathrm{OMA}-1=77.3-74.8 \%$. If assuming only charcoal contributes to supplying the carbon inside the iron matrix, the above values should be close to the measured charcoal value $\mathrm{pMC}_{\mathrm{PH}-1}=101.4 \pm 1.5 \%$. It is possible that the low ${ }^{14} \mathrm{C}$ levels-and the old ages observed - are due to the fossil carbon supplied by the limestone flux. The process of limestone carbon integration inside the iron matrix within the lower half of the furnace may be enhanced by the high-temperature conditions described above.

In the dating of archaeological objects, one of the central issues has been their relation to an archaeological context. If this link is established, it brings a problem of its own, because the context may not be necessarily solid for dating (own-age effects are known to persist for wood-based samples, for instance). The same difficulty is connected with the dating of iron objects because of the charcoal use. However, as pointed out already by van der Merwe (1969:68), freshly cut wood has been preferentially used to produce charcoal for iron production. If this was indeed so, the time lag between the felling of a tree and its use does not considerably add to the own-age effect. Therefore, compared to typical wood or charcoal finds, iron specimens should be more reliable to date. Furthermore, the dating results of iron can possibly be scrutinized by parallel direct datings within the context or by the typological method. Among the most suitable specimens would be, for instance, iron remnants of smelting furnaces and iron nails that have not been reworked and, if found, are typically found in numbers. The amount of such samples is large among the archaeological material. All in 
all, from the archaeological point of view, applying ${ }^{14} \mathrm{C}$ dating of iron objects may be a step further within the framework of context dating, in particular.

\section{CONCLUSIONS AND OUTLOOK}

The $\mathrm{CuO}$ combustion method for extracting the ${ }^{14} \mathrm{C}$ content of iron has been successfully established in the Dating Laboratory of the University of Helsinki. ${ }^{14} \mathrm{C}$ dates of coal-produced reference samples fall within the range 30,900-34,240 BP and indicate some atmospheric contamination within the iron smelting process. Compared to the typically adopted background level of 38,000 BP, the systematic effect for typical Iron and Middle Age ${ }^{14} \mathrm{C}$ ages due to the estimated upper limit of the ${ }^{14} \mathrm{C}$ background in the present process is similar to the typical statistical uncertainty of a ${ }^{14} \mathrm{C}$ measurement (i.e.tens of ${ }^{14} \mathrm{C} \mathrm{yr}$ ).

An elemental analyzer technique has been harnessed to provide carbon contents of iron samples prior to their ${ }^{14} \mathrm{C}$ pretreatment. The technique reproduces well the carbon contents of $0.35-0.70 \mathrm{mg}$ reference samples for high-carbon iron. The technique seems therefore suitable for almost nondestructively examining the carbon contents of such samples. However, the success of the method needs still to be confirmed for low-carbon iron.

The iron smelting experiment—guided by a 200-yr-old recipe—produced an iron sample containing a surprisingly small amount of ${ }^{14} \mathrm{C}$ compared to the value of the fuel used. It is possible that the limestone flux acts as a supply of fossil carbon within the high-temperature smelting process. The involvement of limestone in the process is demonstrated by the outstanding amount of Ca present in the slag and possibly by enhancement of $\mathrm{Ca}$ in iron itself compared to the ore used.

In the future, ${ }^{14} \mathrm{C}$ measurements will be extended to the contexts of the 16th century and beyond while aiming to establish the technique as far as possible in Finland. Particularly, the own-age effects by the charcoal will receive our attention: these are to be explored by comparing the determined ${ }^{14} \mathrm{C}$ ages of iron with the well-known reference dates. It is expected that the ${ }^{14} \mathrm{C}$ dating of iron will contribute particularly within archaeological context dating in Finland.

\section{ACKNOWLEDGMENTS}

This research was supported by the Finnish Cultural Foundation and by the Magnus Ehrnrooth foundation. The authors would like to thank Mr Harri Leppänen from Rautaruukki Oyj for providing the reference samples, Mr Seppo Kallio for arranging the iron smelting experiment, and Mrs AnneMaija Forss and Ms Heidi Nordqvist for careful sample preparation for AMS analyses. We also thank the Centre of Advanced Study at the Norwegian Academy of Sciences and Letters, for which Prof Mika Lavento had a possibility to participate in writing the paper.

\section{REFERENCES}

Cook AC, Wadsworth J, Southon JR. 2001. AMS radiocarbon dating of ancient iron artifacts: a new carbon extraction method in use at LLNL. Radiocarbon 43(2A):221-7.

Hüls CM, Grootes PM, Nadeau M-J, Bruhn F, Hasselberg P, Erlenkeuser H. 2004. AMS radiocarbon dating of iron artefacts. Nuclear Instruments and Methods in Physics Research B 223-224:709-15.

Lavento M. 1999. An iron furnace from the Early Metal period at Kitulansuo in Ristiina, in the southern part of the Lake Saimaa water system. Fennoscandia Archaeologica XVI:75-80.

Palonen V. 2008. Accelerator mass spectrometry and bayesian data analysis [PhD dissertation]. University of Helsinki, Report Series in Physics D148.

Palonen V, Tikkanen P. 2007. An information-efficient Bayesian model for AMS data analysis. Radiocarbon 49(2):369-77.

Peets J. 2003. The Power of Iron-Iron Production and Blacksmithy in Estonia and Neighboring Areas in 
Prehistoric Period and the Middle Ages. Tartu Ülikool: Ajaloo Institut.

Pleiner R. 2000. Iron in Archaeology-The European Bloomery Smelters. Prague: Archeologický ústav AV ÈR. ISBN 80-86124-26-6.

Rinman C. 1794. Korrt underrättelse om sättet att smälta sjö- och myrmalmer uti blästerugnar. Jernkontorets Berghistoriska Utskott H 66, Translitteration och kommentarer Lars J. Hukkinen, Stockholm 1997. ISSN 1101-5284, ISRN JK-BHIST-H-66-SE.

Scharf A, Kretschmer W, Morgenroth G, Uhl T, Kritzler K, Hunger K, Pernicka E. 2004. Radiocarbon dating of iron artifacts at the Erlangen AMS facility. Radiocarbon 46(1):175-80.

Stuiver M, Polach HA. 1977. Discussion: reporting of ${ }^{14} \mathrm{C}$ data. Radiocarbon 19(3):355-63.

Tikkanen P, Palonen V, Jungner H, Keinonen J. 2004. AMS facility at the University of Helsinki. Nuclear Instruments and Methods in Physics Research B 223224:35-9.

Tylecote RF. 1987. The Early History of Metallurgy in Europe. London: Longman.

van der Merwe NJ. 1969. The Carbon-14 Dating of Iron. Chicago: University of Chicago Press. 